УДК 796.078

https://doi.org/10.36906/FKS-2021/08

Белянкин С.Г., Полятыкина Н.Д.

Спортивная школа,

г. Нижневартовск, Россия;

Коричко Ю.В.

ORCID: 0000-0002-5895-6641, канд. пед. наук

Нижневартовский государственный университет

г. Нижневартовск, Россия

\title{
ЭФФЕКТИВНОСТЬ ПРИМЕНЕНИЯ МОДЕЛИ МЕТОДИЧЕСКОГО \\ СОПРОВОЖДЕНИЯ И ОСОБЕННОСТИ РЕАЛИЗАЦИИ ПРОГРАММ \\ СПОРТИВНОЙ ПОДГОТОВКИ В СПОРТИВНОЙ ШКОЛЕ \\ В УСЛОВИЯХ ПАНДЕМИИ КОРОНАВИРУСНОЙ ИНФЕКЦИИ
}

Аннотация. Статья посвящена вопросу, связанному с влиянием пандемии на реализацию программ спортивной подготовки, применением использованных ресурсов, достижением результатов в подготовке спортивного резерва, а также эффективностью применения модели методического сопровождения в спортивной школе путем внедрения дистанционных технологий в подготовке спортивного резерва на удаленном режиме работы, в связи с распространением коронавирусной инфекции - COVID 19. В статье проанализированы некоторые аспекты методического сопровождения подготовки спортивного резерва путем внедрения дистанционных технологий в период пандемии. В статье представлены положительные и отрицательные выводы внедрения дистанционных технологий, связанной с распространением коронавирусной инфекции.

Ключевые слова: подготовка спортивного резерва, эффективность методического сопровождения, дистанционные технологии, новая платформа, пандемия.

Belyankin S.G., Polyatykina N.D.

Sport school

Nizhnevartovsk, Russia;

Korichko Yu.V.

ORCID: 0000-0002-5895-6641, Ph.D.

Nizhnevartovsk State University,

Nizhnevartovsk, Russia

EFFICIENCY OF APPLICATION OF THE MODEL OF METHODOLOGICAL SUPPORT AND FEATURES OF THE IMPLEMENTATION OF SPORT TRAINING PROGRAMS AT A SPORT SCHOOL UNDER THE CONDITIONS OF THE PANDEMIC OF CORONAVIRUS INFECTION

Annotation. The article is devoted to the issue related to the impact of the pandemic on the implementation of sports training programs, the use of resources used, the achievement of results in the preparation of the sports reserve, as well as the effectiveness of the application of the model of methodological support in a sports school through the introduction of distance technologies in the preparation of a sports reserve in a remote mode of work, in connection with the spread of coronavirus infection - COVID 19. The article analyzes some aspects of the 
methodological support of the training of the sports reserve by introducing distance technologies during a pandemic. The article presents the positive and negative conclusions of the introduction of remote sensing technologies associated with the spread of coronavirus infection.

Keywords: training of a sports reserve, the effectiveness of methodological support, remote technologies, a new platform, a pandemic.

В условиях эпидемии многие спортивные учреждения вынужденно переходили на удаленную работу и конечно муниципальное автономное учреждение г. Нижневартовска «Спортивная школа» не стала исключением перехода на дистанционный режим работы в условиях новой платформы. В настоящее время велико значение и важность этой платформы от создания условий для смены тренировочного процесса из просторных, специализированных залов офлайн-режима в условия домашней подготовки, в которой создается атмосфера привлечения спортсменов к регулярным занятиям в онлайн - режиме и режиме грамотного методического сопровождения [3, с. 53, 4, с. 247].

Поэтому мы считаем, что на сегодняшний день можно смело обозначить эффективность применения модели методического сопровождения с применением дистанционных технологий в онлайн -режиме.

Организация методического сопровождения в помощь тренеру и администрации была организована с помощью возможностей удаленной локальной сети». Удаленный режим работы на компьютеры администрации спортивной школы, начальникам отдела, заведующим отделений, инструкторам-методистам установлен в домашних условиях. Вся работа структурных подразделений была распределена в соответствии с номенклатурой дел и сформированных папок под определенными номерами. Организованный таким образом порядок «номенклатуры» в локальной сети предоставил незаменимую помощь в работе специалистам.

Было определено методическое сопровождение программ спортивной подготовки внутренними локальными актами спортивной школы:

- проведен мониторинг технических возможностей реализации режима онлайн у каждого спортсмена и тренера;

- разработан план мероприятий, направленных на обеспечение выполнения программ спортивной подготовки;

- определена совместно с тренерами система организации спортивной подготовки со спортсменами во время онлайн-режима: виды, количество работ, форма взаимодействия участников процесса спортивной подготовки (дистанционная, удаленная и др.), сроки получения заданий спортсменами и предоставления ими выполненных работ;

- проведено информирование тренеров, спортсменов, родителей (законных представителей), иных работников спортивной школы об организации её работы во время онлайн-режима, в том числе через официальный сайт школы, мессенджеры;

- организован контроль за корректировкой годового плана - графика спортивной подготовки, в соответствии с программой спортивной подготовки;

- разработаны рекомендации для участников тренировочного процесса по организации работы во время дистанционного режима спортивной подготовки;

- организован контроль за использованием тренерами дистанционных форм подготовки спортивного резерва, осуществление методического сопровождения и контроль за внедрением современных технологий, методик, с целью реализации в полном объёме спортивной подготовки; 
- осуществлен контроль спортивной подготовки за спортсменами;

- организована воспитательная, научно-методическая деятельность участников спортивной подготовки коллектива в соответствии с планом работы;

Была организована работа по методической поддержке тренеров, которая проводилась в электронном формате:

- подготовка и проведение онлайн - совещаний, советов и консультаций;

- разработка методических рекомендаций по составлению методических разработок в помощь тренерам совместно с ФГБОУ ВО Нижневартовский государственный университет;

- внедрение современных методик обучения на основе интерактивных технологий;

- участие тренеров в вебинарах и видеоконференциях городского, окружного, российского уровня с участием с профессорско-преподавательского состава факультета физической культуры и спорта ФГБОУ ВО Нижневартовский государственный университет для оказания методической поддержки и обмена опытом.

- повышение квалификации тренеров на базе ФГБОУ ВО Нижневартовский государственный университет;

- консультирование тренеров по применению технологий индивидуальной поддержки одаренных спортсменов и другим методическим вопросам;

- организован мониторинг методических разработок тренеров на различные темы и размещение их на сайте учреждения и других статистических сведений;

- организован контроль результатов подготовки спортивного резерва спортсменов. Офлайн - выполнение и проверка заданий, замечания и комментарии по ним, тестирование, анкетирование, опросы. Онлайн - опросы посредством проводились посредством видеоконференцсвязи.

Контроль выполнения заданий спортсменами осуществлялся тренерами дистанционно с применением таких форм контроля, как просмотр видеофайлов с выполнением упражнений, анкетирование спортсменов, вопрос-ответ в режиме телефонной связи, беседы со спортсменами и родителями/законными представителями. Контроль работы тренера осуществлялся в форме опроса по способам ведения тренировочного процесса, на какой платформе и с помощью каких методов осуществляется подготовка спортивного резерва. Проверка ведения подготовки спортивного резерва включает в себя подключение работников администрации учреждения к видео тренировочных занятий тренеров контроль ведения документации, просмотр конспектов занятий и других материалов.

Было проведено заседание комиссий по аттестации работников в онлайн-режиме, организована работа комиссии по переводу спортсменов и приемной комиссии, велась работа по комплектованию спортивных групп, обобщению опыта в программе презентаций, проведены открытые мастер - классы, проводился мониторинг кадрового потенциала, соревновательной деятельности, награждений и поощрений, оснащение оборудованием, инвентарем, экипировкой, подготовка статистической отчетности, проводился контроль за исполнением требований выполнения мероприятий по недопущению распространения коронавирусной инфекции в условиях дистанционных технологий и многое другое.

Тренерам нашего учреждения при реализации программ спортивной подготовки с применением дистанционных технологий рекомендовалось планировать тренировочную деятельность в дистанционном режиме, создавать простейшие, нужные для спортсменов комплексы упражнений и задания:

-выражать свое отношение к спортсменам в виде текстовых или аудио рецензий, устных онлайн-консультаций, а также пользоваться площадками, платформами, сайтами, при помощи 
которых можно было полноценно организовать дистанционные технологии по проведении тренировочного процесса по видам спорта [1, с. 19, 2, с. 23];

-дифференцированно работать с каждым спортсменом на программе Zoom;

-определять обратную связь и определять эмоции спортсмена, проявление интереса, вовлеченности, степень успешности (чаты, форумы, кейсы, творческие задания, проекты и другие интерактивные форматы);

- мгновенно исправлять ошибки и показ.

-проводить консультации в разных формах, в зависимости от уровня подготовленности дистанционных ресурсов спортсменов или в онлайн - режиме через тот или иной мессенджер, или записи объяснений и комплексы заданий по видео с полным звуковым описанием.

-ежедневно поддерживать связь через родительский чат WhatsApp, Viber и другие.

-работать по заранее подготовленному плану работы со спортсменами и формами проведения подготовки спортивного резерва

-организовывать ежедневный мониторинг участвующих в тренировочном занятии с применением дистанционных технологий.

-применять различные формы работы, как со спортсменами, так и с тренерским составом проведения подготовки спортивного резерва - это: самостоятельные тренировочные занятия в соответствии с помесячным рабочим тематическим планом программы спортивной подготовки по виду спорта, разработанной на основании федеральных стандартов спортивной подготовки по виду спорта на платформе Zoom; промежуточное тестирование по ОФП и СФП;

-лекции с элементами презентаций; изучение дистанционных технологий (Интернет ресурсы, электронные носители, бумажные носители); конференции в чате; коллективные проектные работы в презентациях; индивидуальные проектные работы; проведение мониторинга; проведение мастер - классов; участие в конкурсах, викторинах; проведение работы приемной комиссии в дистанционном формате; консультации.

-организовывать тренировочные занятия в виде показательных видеосюжетах, которые транслировались в рамках общегородских спортивных мероприятиях в онлайн-режиме.

-проводить обмен результатами работы по подготовке спортивного резерва посредством использования облачных технологий (Яндекс.Диск, Облако на mail.ru).

-проводить обсуждение результатов работы проводилось в соцсетях и через мессенджеры: WhatsApp и Viber.

Однако, независимо от уровня всей подготовки к переходу в новый режим платформы у данного вида дистанционной работы спортивной подготовки определились плюсы и минусы в реализации программ спортивной подготовки.

К преимуществам можно отнести:

- развитие самодисциплины и самообразования,

-освоение инновационных технологий и средств коммуникаций, мобильность и оперативность между тренером и спортсменом,

- развитие самодисциплины и самообразования,

-использование дистанционных технологий в работе с каждым спортсменом индивидуально,

-мгновенный доступ к тренировкам и иным электронным ресурсам,

-в тренировочный процесс внедрена реализация дистанционных технологий и новых форм работы со спортсменами в спортивной подготовке.

Также можно отметить, что подготовка и участие в онлайн-режиме в целом предоставляет более детально отрабатывать элементы. 
Кроме того, к преимуществам дистанционных технологий относятся такие характерные черты как гибкость, модульность, технологичность, обновление роли тренера, повышение мотивации и самоорганизации спортсменов, что позволяет повысить эффективность самостоятельной работы (анализировать свои ошибки и исправления их, осваивать теорию и практическую часть тренировочных занятий).

Использование современных интернет-технологий позволяет сегодня сделать работу спортивной школы, открытой для родителей, предоставить услугу дистанционного взаимодействия участников тренировочного процесса и таким образом усилить деятельностную составляющую работы с родителями.

При такой организации у спортсменов в период ограничительных мероприятий не только сохранится спортивная форма, но и будет обеспечена необходимая двигательная активность, которая так необходима для успешного освоения программы спортивной подготовки.

Были определены и минусы удаленного режима с применением дистанционных технологий:

-отсутствие прямого контакта с тренером и спортсменом группы,

-трудности в плане учета особенностей личности,

-слабый доступ к Интернету,

-малый объем практических занятий, нацеленных на отработку. Практически все действия спортсмен проходит самостоятельно. Это требует развитой силы воли, ответственности и самоконтроля. Обучение специальным видам спорта, предполагающим большое количество практических заданий, дистанционно, практически невозможно. Даже самые современные методики не заменят «живую» практику,

-недостаточная компьютерная грамотность. Не все желающие заниматься выбранным видом спортом имеют персональный гаджет и выход в сеть интернет.

При удаленном режиме работы с применением дистанционных технологий контакт друг с другом и с тренером минимален. Поэтому такая форма удаленный работы не совсем подходит для развития коммуникабельности, уверенности, навыков работы в спортивной команде, спортивной группе.

Также, среди минусов удаленного режима работы с применением дистанционных технологий стоит отметить снижение коммуникационной культуры в развитии личности. При наличии особых психологических показателей развития личности (например, одиночество в реальном мире) возможен переход в интернет-зависимость (как у спортсмена, так и у тренера). Также серьезной проблемой является психологическая адаптация к удаленному режиму при отсутствии личного контакта спортсмена с тренером, а также отсутствие навыков самоорганизации.

Эффективность применения методического сопровождения с применением дистанционных технологий при выходе на офлайн-режим спортивной подготовки выявлена после ведения замеров подготовки спортсменов, которая выражена в:

-промежуточных результатах контрольных нормативов по видам спорта, с учетом предыдущих замеров КПН по ОФП и СФП. Статистические данные показали $100 \%$ уровень физической активности;

-показанных высоких результатов на спортивных соревнованиях, количество спортсменов в рейтинговом подсчете медалей составило $80 \%$;

-аттестации специалистов и повышении методической грамотности $100 \%$;

-участия в семинарах, конференциях, публикациях 100\%, 
-приросте заинтересованности всех тренеров к регулярному повышению своей компетентности в условиях удаленного режима работы с применением дистанционных технологий.

-стабильность коллектива и интерес к методической работе, образование конкурентоспособности друг с другом и другими учреждениями в повышении своего профессионального уровня и эффективной подготовке спортивного резерва.

По мере необходимости наработанный опыт используется в период пандемии и в настоящее время в период действия ограничительных мер.

Как тренеры, так и спортсмены стали использовать дистанционные технологии при работе или отработке со спортсменами в отпуске или на каникулах, в период самоподготовки, при отработке элементов перед соревновательной деятельностью.

Увеличился рейтинг внимания и заинтересованность к спортивной школе, благодаря практической значимости методического сопровождения. Эффективность данного направления была преимущественно отмечена числом подписчиков группе «Вконтакте» (https://vk.com/olimpianv).

Усиленная мера безопасности, направленных на предотвращение корона вирусной инфекции, использованию средств индивидуальной защиты заявляет о повышенной заботе своего здоровья спортсменов, а также работников. Увеличен проявленный интерес к спорту, в связи с накопившейся потребностью, намного меньше стали пропускать тренировочные занятия спортсмены без уважительной причины. Сформирована эффективная системы подготовки спортивного резерва, обеспечивающей непрерывную подготовку спортсменов с применением дистанционных технологий.

Повысилась инновационно-методическое сопровождение кадрового потенциала в учреждении, выраженная в следующих ресурсах:

- поддержка инновационно-методической деятельности тренера;

- методические мероприятия, тематические семинары;

- методические конкурсы, конкурсы профессионального мастерства;

- система наставничества над молодыми тренерами;

- информационно-методические ресурсы;

- реализация инновационных проектов;

- экспертно-аналитическая деятельность;

- поддержка протестированных более успешных онлайн-практик.

Таким образом, разработанные мероприятия и практический опыт по внедрению методического сопровождения подготовки спортивного резерва в реализации программ спортивной подготовки в условиях МАУ г. Нижневартовска «Спортивная школа» стали способствовать раскрытию творческого потенциала тренеров по спорту и инструкторов методистов, обеспечивать высокое качество подготовки спортивного резерва в удаленном режиме с учетом дистанционных технологий, а также положительную динамику практически всех показателей.

\section{Литература}

1. Коричко Ю.В., Давыдова С.А., Полятыкина Н.Д. О взаимодействии вуза и профессионального сообщества в сфере физической культуры и спорта // Традиции и инновации в образовательном пространстве России: Материалы VII Всероссийской научнопрактической конференции. 2018. С. 18-20. 
2. Коричко Ю.В., Полятыкина Н.Д. Эффективность внедрения педагогической модели методического сопровождения детско-юношеского спорта в г. Нижневартовске // Физическая культура: воспитание, образование, тренировка. 2019. №3. С. 23.

3. Сердюкова Н.Д. Особенности методического сопровождения детско-юношеского спорта в условиях модернизации подготовки спортивного резерва в муниципальном образовании// Физическая культура: воспитание, образование, тренировка. №1. 2017. С. 53.

4. Юдин Б.Л., Машичев А.С. Физические нагрузки во время эпидемии: правила и ограничения // Молодой ученый. 2020. №21(311). С. 246-247.

(C) Белянкин С.Г., Полятыкина Н.Д., Коричко Ю.В., 2021 